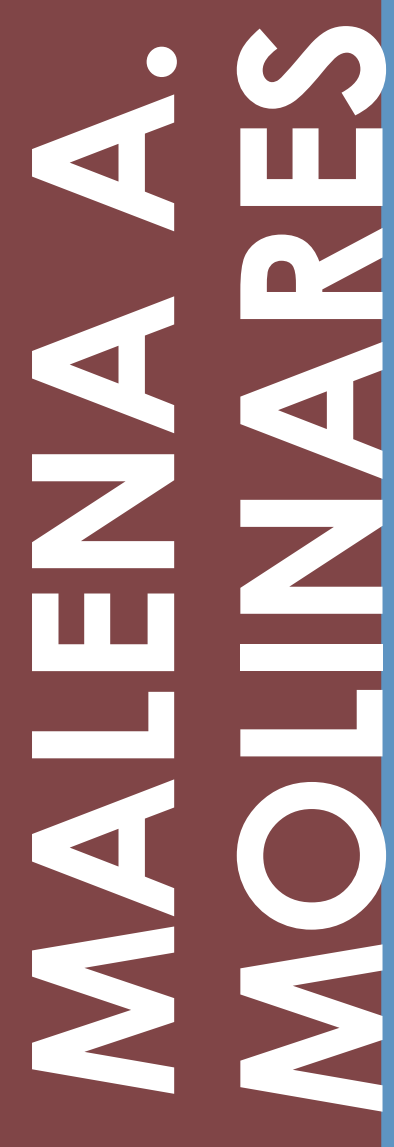




\section{VINCULACIONES Y BIFURCACIONES ENTRE EL ARTE Y EL DISEÑO GRÁFICO: UNA ENCRUCIJADA}

\section{Links and divergences amongst art and graphic design: a crossroad Malena Andrade Molinares}

\section{Resumen}

El presente ensayo postula, como eje detonador de toda la disertación reflexiva, establecer vínculos y bifurcaciones entre el arte y el diseño. Comenzaremos por tratar de establecer una definición de lo que se entiende por arte, luego una definición de diseño gráfico y, por último, un apartado sobre cómo se conectan estas dos disciplinas del saber humano, hasta dónde se auxilian y los espacios que las delimitan y las hacen "lo mismo y lo otro", sin ánimos de mostrarlas antagónicas o como usurpadoras de sus linderos, lejos de esta idea aseguramos que se comunican y se hermanan para luego desarticularse y recuperar de este modo su hegemonía, dando la oportunidad de reflexiones como las que continuación se presentan.

\section{Palabras clave:}

arte, diseño, vínculos, comunicación, fronteras.

\section{Abstract}

This essay appoints links and divergences concerning art and design. It begins by establishing a definition of what is understood like art, then a definition of graphic design and, finally, a section on how these two disciplines are connected, how far they are aided and the boundaries that makes them "the same and the other," without placing them like opposed or as supplanters of the other. We prove that they communicate and recover their control.

\section{Key Words:}

art, desing, links, communication, borders.

\section{Biografía de la Autora:}

Doctora en Ciencias Humanas (ULA). Magíster en Literatura Iberoamericana (ULA). Licenciada en Educación (ULA).Licenciada en Letras (ULA). Profesora de la Universidad de Los Andes (ULA Venezuela) de la Facultad de Arte. Profesora de la Maestría en Educación, mención Informática y Diseño Instruccional (ULA). Docente invitada del Doctorado en Ciencias de la Educación (UPEL). Investigadora PEII Nivel B del MPPEUCT. Correo: malena.victor@gmail.com 
"Abrid un periódico cualquiera: no dejaréis de encontrar en él una o dos columnas consagradas al teatro y a la música. Encontraréis también, la mayoría de las veces, un suelto relativo a alguna exposición artística, a la descripción de un cuadro, de una estatua, y sin duda alguna, el análisis de novelas, cuentos y poemas nuevos." León Tolstoi. ¿Qué es el arte?

\section{Arte: forma connotativa de sugerir}

El polémico debate entre lo que representa el arte y el diseño, como disciplinas humanas que se auxilian y se complementan, es uno de los temas más discutidos en los diferentes ámbitos académicos donde fluctúan estas dos formas de saberes. Señalar donde comienza uno y termina el otro es realmente un reto; sin embargo, ambos campos poseen sus explicaciones internas que les permiten ciertos devaneos, para permearse, o relacionarse desde una sujeción intrínseca, pero nunca se sustituyen, tampoco se deben asumir como disciplinas que se homologan y se convierten en lo mismo. Aclaremos, se reúnen en un punto, pero luego recuperan sus espacios, nunca se suplantan.

Comencemos tratando de reflexionar y cuestionar los terrenos del arte y el diseño por separados. Iniciaremos con un acercamiento al concepto de arte, como punto de honor de esta disertación.

El arte desde su esencia más general busca desaguar un sentir que anega el alma del creador pero, para que este se concrete debe existir también la necesidad intrínseca de convertir una idea en realidad o remedo de alguna verdad. Resolver el asunto de la definición de arte en este ensayo es reduccionista, pues tal vez existan tanta definiciones como interesados en el tema.

Empezaremos diciendo que quienes producen obras, en cualquiera de las manifestaciones estéticas, desahogan su alma y transcriben espejos de su pensamiento bocetos in- acabados de sus ideas, genuinas, inconclusas pero con la impronta de suspiros, desvelos y reflexiones que dejan huella en la obra, testigos silenciosos de producciones artísticas las cuales deben despertar los sentidos de quienes las contemplan. El arte nos introduce en las insondables vaguedades del espejismo de la verdad. La idea de irreal que representa el arte es a su vez como el humo fugaz que revela misteriosamente ese placer concéntrico que agudiza los sentidos de los espectadores como fin y esencia catártica, cuya definición no es más que una entelequia, es decir, el arte se basta así mismo para definirse.

Algunas veces estimamos como únicas e irrepetibles las obras artísticas, esta sentencia puede ser riesgosa, pues en ocasiones los creadores se ven en la obligación de repetir sus obras, bien sea para la comercialización o porque buscan de alguna manera alcanzar la perfección. El arte en sus diversas formas imita, pero en medio de ese remedo juzga e interviene lo imitado, pues nunca conseguirá reproducir con exactitud lo emulado, es aquí donde radica su grandiosidad en la imposibilidad de crear una realidad perfecta, podríamos citar a Fuentes (1999), quien sostiene que "el artista no refleja la realidad: la funda" (p.177), y según Morín (2002): "Las artes nos introducen en la dimensión estética de la existencia y según el dicho que dice que la naturaleza imita lo que la obra de arte propone, nos enseñan a ver mejor el mundo desde un punto de vista estético" (p. 47).

Ahora bien, en este infructífero empeño por tratar de comprender lo que significa el arte, es importante señalar que la misma palabra ha sufrido los embates de los cambios y transformaciones culturales que se asoman desde la década los sesenta hasta la presente fecha, es así como se ha resemantizado transformando su significando, que a decir de Gianni Vattimo es fruto de la postmodernidad y del mismo fin de los relatos, pues ha permitido que el arte se contonee por otros escenarios, rebosó los museo y se adueña de diversos espacios: la calle, los bulevares, las plazas, los árboles, las paredes, las universidades, los nichos acadé- 
micos y, en fin, se escurrió y se convirtió en diáspora que revoletea por donde su libertad le permite. Tal como lo asevera Baudrillard (1997) “el arte está en todas partes. Está en los museos, está en las galerías, pero también está en la banalidad de los objetos cotidianos, está en las paredes, está en la calle, como es bien sabido, está en la vanidad hoy sacralizada estetizada de todas las cosas" (p. 49).

Pero esta rebeldía del arte ha traído como consecuencia que se pierda, en ocasiones, los criterios que sirvieron para definir qué es arte y qué no. En este punto entramos en conflicto, pues de esta forma se podría calificar casi de insolente que, a todo lo que se haga o a cualquier cosa se le llama arte. La misma palabra ahora tiene cabida en todas las actividades humanas y en los quehaceres menores y hasta insignificantes, así de forma deportiva y hasta transgresora e irrespetuosa escuchamos, el arte de la cocina, el arte de jugar, el arte de amar (existe un libro con este título de Erich Fromm), el arte de limpiar y todo eventualmente puede ser arte, esto hace aún más escurridizo y sumamente dificultosos asir el concepto.

El asunto de tratar de definir conceptualmente el arte es de larga data, y más viejo es el propósito de establecer su taxonomía, pues ya desde la Edad Media se comienza a pensar en una posible clasificación de Bellas Artes, tal como señala (García, 2007):

La historia de la clasificación de las artes es un verdadero "quita y pon". En la Edad Media eran siete: gramática, retórica, lógica, aritmética, geometría, astronomía y música. Ciencias y artes combinadas. Las Bellas Artes en el siglo XVIII fueron conocidas como pintura, escultura, música, literatura y danza. La discutida arquitectura se metía donde podía. En el siglo XV las obras del escultor se las denominaron "arti di disegno" por utilizar el dibujo (s/p).

Según nos explica el autor mencionado en el párrafo anterior, la idea primogénita sobre clasificar las artes ha cambiado, y si pensamos en estos últimos siglos esta clasificación se complica aún más, pues con el desarrollo de la fotografía, el cine, el teatro, la danza, la ópera, los videos y diversidad de multimedia, surge una nueva era, lo cual sugiere que no es tan fácil determinar dónde comienzan las artes y cuál es su radio de acción dentro de las revoluciones tecnologías, dando paso a nuevas formas de construcciones artísticas que transforman el pensamiento y los esquemas rígidos empiezan a tambalearse.

$\mathrm{El}$ arte consagra una realidad paralela. $\mathrm{Su}$ función epistemológica y estética en general puede constituirse como la columna vertebral de lo que postula como esencia, que adquiere visos de constante búsqueda por fusionar de forma perfecta, colores, movimientos, notas musicales, formas, líneas, construcciones o la implementación de lo tridimensional como aspecto que caracteriza a la escultura pero también a otras manifestaciones artísticas que han emulado ciertos aspectos de este arte. Sin olvidar que las manifestaciones estéticas (en cualquier de las épocas que se haya producido) permiten comprender el momento socio-históricos, lo que algunos denominan el espíritu de la época, pues en ocasiones éste se trasforma en un arma implacable y muy temida de denuncia social.

Según Eco (2009): “el arte no es más que representación y formación de una materia pero la materia se forma de acuerdo con un irrepetible modo de formar, que es la espiritualidad misma del artista hecha estilo" (p. 205). De aquí que, consideraciones tan antiguas soportan la idea que el arte es único e irrepetible, como única e irrepetibles son las particulares huellas digitales, que se corresponden indefectiblemente con las obras artísticas de los creadores.

\section{Diseño gráfico: forma denotativa de comunicar}

El diseño gráfico es una disciplina inserta en la sociedad, y como tal dará respuesta a problemas de comunicación que ésta se plantea, su función principal dentro de la comunicación es denotativa, no puede ni debe dejar nada a la libre interpretación del 
público, debe explicitar el mensaje: ser claro, conciso, coherente y directo.

El diseño gráfico se abreva y se refresca del arte, se apropia de sus características, hace usufructo de lo que esta disciplina le ofrece y lo ajusta a sus necesidades específicas, que básicamente son comunicar visualmente de forma clara y precisa una idea o un mensaje, se entreteje con el concepto de comunicación, pues su función primordial es trasmitir contenidos que poseen una carga comunicativa de interés para algún target específico, por ser una disciplina visual.

Entonces, podríamos decir que por diseño gráfico entendemos las diferentes práctica, que se auxilian de la tecnología, para desarrollar mensajes visuales que contienen implícitamente elementos que informan y persuaden, contemplando aspectos estilísticos, estéticos, decorativo y de identidad. Por diseño "se entiende todo esfuerzo consciente para establecer un orden significativo" (Vilchis, 2002, p. 33). Sin embargo, también se propone orden en otras realidades y no son diseño, por lo que queda claro que definir esta disciplina va más allá de mirarla sólo como una forma sistemática de resolver un asunto visual.

\section{Según Costa (2009):}

El diseño es el conjunto de disciplinas proyec-
uales ligadas a la construcción, la producción, la
ormalización y la difusión de bienes y servicios
información. Dichas disciplinas están destina-
das, cada una desde su especialidad a la mejora
de la calidad ambiental, material, estética, lúdica y
ultural del entorno y la vida de los individuos en
ociedad (p. 4).

Partiendo de esta cita, podríamos aseverar que crear una expresión gráfica, ya sea desde el diseño editorial, la señalética, el diseño de ilustración, narrativa gráfica, diseño tridimensional, o cualquier otra forma que implique el diseño gráfico, está indefectiblemente ligado al arte, pues supone para el profesional de esta disciplina entender la comunicación como el fin primordial de esta área del saber humano. El diseñador gráfico deberá elaborar mensajes que sean claros, comprensibles para un público específico. Un producto que surge para dar respuesta a una necesidad visual debe ser explicito, en este caso no hay espacio para lo connotativo, ya que el diseño dentro de sus principales características debe ser directo, expresar de manera clara el mensaje que se propone transmitir.

Lo que se plantea en el párrafo anterior se concatena con lo señalado por Montero (2004), quien específicamente en un artículo titulado "Cartarsis visual el diseño gráfico como agente de cambio social”, señala que:

El Diseño Gráfico es todo proceso de transmisión de mensajes específicos y determinados a una audiencia del mismo modo específica y determinada, valiéndose de medios visuales, con el objeto de informar, instruir o persuadir. El resultado del mensaje gráfico debe ser capaz tanto de informar a la audiencia, como de transmitir la carga emocional necesaria para lograr la respuesta en el público que conlleve a cambios de conducta. Es por ello que el Diseño Gráfico es un proceso vital en la evolución de las sociedades por su poder de cambio y contundencia en las masas. Esta debe ser una premisa fundamental para todo estudiante o profesional de esta disciplina.

En este sentido se puede relacionar el diseño gráfico con todo lo que la sociedad comporta implícitamente, pero muy especialmente con esa necesidad de comprender, de conocer, de saber y entender algo, y la vía más expedita es lo que comunica el diseño a través de sus distintos modos expresivos: ya sea publicitario, de identidad, señalética, marcas, isologotipos, diseño de multimedia y web, diseño de envase, tipográfico, cartelería, entre otros, la lista no se detiene acá, pues como sabemos el diseño gráfico anega todo cuanto hay a su paso, mas aún en un mundo globalizado que necesita informarse constantemente y que se sitúa en un momento de consumo que ha desbordado cualquier otra época. El diseño entonces es, la disciplina que se encarga de mostrar por medio de un proceso sistemático (que tiene sus métodos y técnicas) un mensaje que implícitamente tendrá un público receptor $\mathrm{y}$ desde luego una intencionalidad precisa. 


\section{Las fronteras entre el Arte y el Diseño: Una aproxima- ción explicativa}

Reflexionar sobre las fronteras tenues y borrosas existentes entre el diseño gráfico y las artes visuales es un asunto espinoso y difícil de dirimir a simple vista. La encrucijada que ha surgido al buscar semejanzas y diferencias entre estas dos disciplinas está fundamentalmente unida al hecho de que las definiciones de arte y diseńo intrínsecamente están constituidas por una resemantización interior de sus propios conceptos, camuflándose una con la otra, perdiendo espacio y borrando los contornos, haciéndolas lo "mismo y lo otro" confundiendo, muchas veces, sus funciones y significaciones, es claro que existe una relación indisoluble, como cuando se liga el agua y el azúcar, al igual que esta solución el arte y el diseño se configuran como aliados que se atan y se implican recíprocamente.

Las vinculaciones y bifurcaciones que se dan entre el diseño y el arte, surgen debido a una línea imprecisa entre estas dos disciplinas que están relacionadas, ciertamente, pero nunca se sustituirán, aun cuando se nutran, se auxilien y hasta se intervengan en sus campos. Esta demarcación fronteriza, huidiza y difícil de asir, se debe a que ambos conceptos son pensados para ser apreciados desde lo visual, aun cuando las nuevas tecnologías comienzan a incorporar elementos que son perceptible a través de los otros sentidos (auditivos, kinestésicos o valiéndose de los avances multimedia y en algunos caso del braille) pero es básicamente la visión el sentido hegemónico encargado de transferir la información, planteada por el arte y el diseńo, al cerebro.

De lo anterior se podría deducir que el diseño gráfico tiene un propósito más establecido y preciso que el arte: comunicar un mensaje, cuyo objetivo será en definitiva resolver un problema, es decir que, aunque los diseñadores deben valerse de la intuición para producir lo deseado, deberán también ser ecuánimes en lo que proyectan elaborar, en este punto existe otra diferencia con el arte, éste es subjetivo, nace de un fuero interno y no busca solucionar un problema sino más bien darle rienda suelta a la creatividad, pues como asegura Guilera (2011) creatividad es: "percibir, idear, expresar y convertir en realidad algo nuevo y valioso" (p. 30).

Por lo cual, quienes producen arte o diseño requieren ser creativos, en este punto se vinculan y por momento se confunden las funciones de estas dos disciplinas. Diseño y arte se hermanan y acercan en una hibridez desconcertante, confundiendo los criterios objetivos que las definen, transforman la creatividad en la capacidad que hace desconocer dónde comienzan y terminan sus rasgos característicos.

El arte, por su misma naturaleza, sugiere, insinúa y hasta devanea, muchas veces ni siquiera es explicito, es más connotativo que denotativo. Contrariamente el diseño es directo, no sugiere, ya que necesita transmitir con claridad un mensaje, persuadir y convencer, para no dejar espacio a la duda o la interpretación caprichosa del público receptor. El arte puede balancearse entre sugerir y dirigir un mensaje explícito o no.

A lo largo de la historia de la estética se ha tratado de revisar el concepto de arte, y en incontables ocasiones se asume su definición como aquel objeto de características únicas e irrepetible, poseedor de una impronta que lo hace en términos de Kant "sublime", rodeado de una aura imperceptible que origina algún sentimiento en quien lo observa solo por contemplación, o para analizarlo desde lo epistemológico. El arte genuinamente estuvo revestido de unas especificidades que le otorgaban un estatus superior, por sobre otras áreas y producciones humanas, pues su valor estético le permitía cierta hegemonía. Sin embargo, con el correr del tiempo, el "fin de los relatos" y los paradigmas emergentes la situación se ha transformado, entonces el arte comienza a inundar lo cotidiano, haciendo dudar del verdadero lugar de éste, ante tal dilema filósofos, 
estetas, críticos y artista visuales no están muy claros sobre la definición del mismo.

El arte contemporáneo, en cualquiera de sus manifestaciones, se ha convertido en una panoplia que se funde en un todo, donde la sinestesia y las sensaciones secundarias comienzan a ser importantes, generándose una interacción más dinámica entre el producto artístico y las sensaciones del receptor o público. Entonces, el observador desde sus intersubjetividades será finalmente quien dictamine lo qué es arte o no. El diseño también se vale de estas nuevas formas que ofrece la ciencia y la tecnología, pero su intención no será conmover, despertar sentimientos, ni animadversiones, su función es directa se aleja de los sentimientos y busca transmitir un mensaje, convencer y persuadir, pues el diseño hace un esfuerzo para que sus productos sean útiles a la gente, procurando informar, publicitar, vender, o anunciar una campaña, entre otras funciones.

El arte y el diseño gráfico, indefectiblemente, se encuentran dentro de una cultura, es tan llana y simple esta conjetura que los vincula, pues como señala Foucault "el mundo forma una cadena consigo mismo", por lo que definir estas disciplinas y establecerles demarcaciones precisas es casi imposible, como sostiene Vidal (2013): "El diseñador ya consolidado, puede trascender al territorio del arte, sea mediante técnicas tradicionales o digitales, para revertir su función de comunicador y creativo".

La aseveración expuesta por Vidal, citado en el párrafo anterior, conllevan a la interrogante: ¿Será que el diseño ha violentado las fronteras del arte para formar parte de éste o, si el artista ahora se ha transformado en un diseñador, a fin de romper con los esquemas tradicionales que encapsulaban su actividad como una acción meramente elitista, traspasando linderos y saliéndose del marco establecido de lo que la academia aceptaba como hecho artístico? En este sentido, la idea expuesta por Pontis (2009) contribuye a disipar un poco el asunto: "El diseño gráfico y el arte son dos disciplinas distintas. Sin embargo, en la actualidad todavía existen dudas sobre sus di- ferencias y aplicaciones. En cierto sentido, el diseño gráfico continúa estando bajo «el ala» del arte; y como teniendo que "pedir permiso» para tener su propio espacio".

Lo expuesto por esta investigadora está relacionado con el hecho que el diseño es un espacio idóneo para la multidisciplinariedad, es decir, cuyo accionar se concatena con otras áreas del saber humano, no es monodisciplinar, y menos aún en un mundo abarrotado por los avances de la informática, donde el diseño encuentra su campo más fecundo para elaborar mensajes, cumpliendo a cabalidad su función comunicativa.

\section{Palabras finales}

Por último queremos señalar que, el diseño y el arte se vinculan y se bifurcan en una nebulosa que hace muy difícil establecer límites claros y precisos, se auxilian y se distancian en sus empresas, contribuye de forma decisiva en esta vinculación los nuevos avances de la tecnología. Las funciones y propósitos de estas disciplinas se hacen una masa amorfa difícil de simplificar con una definición precisa. Pretender establecer las especificidades que limitan y conceptualizan al arte y al diseño hoy más que nunca es, transitar por un camino espinoso, pues día a día estas dos formas expresivas cumplen un objetivo que las integra: mirar el mundo de forma más holística, con el propósito de consolidar bases para un sistema amplio, plural y complementario.

Surge entre el arte y el diseño una frontera que demarca sus linderos, pero a su vez dialogan como buenos vecinos, generando una paradoja de comunicación e intercambio, permitiendo que estas disciplinas se concedan ciertos permisos o licencias para ocupar espacios que no pertenecen a su perímetro, pero que genera un territorio abierto y libre donde entran y salen los diseñadores y artistas, toman prestado lo que les interesa para conseguir algo original y novedoso en sus productos, transitan entonces entre realidades que les son comunes: trazo, dibujo, línea, color, espacio, que migran a otros mundo y luego 
retornan a su espacios sin dejar de sońar con ese otro mundo que conocen, palpan, sientes con el cual se han parangonado, pero que definitivamente deben abandonar para recuperar sus áreas y, saber de manera consciente que en otro momento deberán hacer de nuevo el viaje para consolidar sus objetivos: el diseño; comunicar de forma denotativa visualmente mensajes y, el arte; figurar mundos connotativos que coquetean con lo que en definitiva solo sabrá el espectador.

\section{Bibliografía:}

Baudrillard, J. (1997). La ilusión y la desilusión estéticas. Caracas-Venezuela: Monte Ávila Editores Latinoamericanos.

Costa, J. (2009). Manifiesto del Diseño Gráfico del siglo XXI. PDF. Impreso.

Eco, U. (2009). La definición del arte. España: Ediciones Martínez Roca.

Fuentes, C (1999). Los años con Laura Díaz. Santa Fe de Bogotá Colombia: Alfaguara.

García, J. (2007). “Arte y Diseño”. Revista intenorgrafico de la división de Arquitectura y Diseño de la Universidad de Guanajuato: México. Recuperado de:

http://www.interiorgrafico.com/edicion/ tercera-edicion-mayo-2007/arte-y-diseno-grafico.

Guilera, L. (2011). Anatomía de la creatividad. Escola Superior de Disseny ESDi

Montero, J. (2004). "Cartarsis visual el diseño gráfico como agente de cambio social”. En Revista de Estética. Nº 6.

Morín, E (2002). La cabeza bien puesta. Repensar la reforma. Reformar el pensamiento. Buenos Aires: Ediciones Nueva Visión.

Pontis, S. (2009). "Qué es y qué implica la investigación en Diseño”. FOROALFA.

Recuperado en: https://foroalfa.org/articulos/que-es-y-que-implica-la-investiga- cion-en-diseno

Vidal, E. (2013). "El diseño gráfico como objeto de estudio y sus significados". FOROALFA. Recuperado en:

https://foroalfa.org/articulos/el-diseno-grafico-como-objeto-de-estudio-y-sus-significados.

Vilchis, L. (2002). Metodología del diseño. Fundamentos teóricos. México: Editorial Claves Latinoamericanas.

Tolstoi, L. ¿Qué es el arte? Libro en PDF. Impreso, 91 págs. 